\title{
Modelling Resilient Modulus Seasonal Variation of Silty Sand Subgrade Soils with Matric Suction Control
}

\author{
Farhad Salour $^{1}$, Sigurdur Erlingsson ${ }^{2}$, Claudia E. Zapata ${ }^{3}$ \\ ${ }^{1}$ Pavement Technology, Swedish National Road and Transport Research Institute, VTI \\ 58195 Linköping, Sweden \\ Division of Highway and Railway Engineering, Royal Institute of Technology, KTH \\ SE-100 44 Stockholm, Sweden \\ farhad.salour@vti.se \\ ${ }^{2}$ Pavement Technology, Swedish National Road and Transport Research Institute, VTI \\ 58195 Linköping, Sweden \\ Faculty of Civil and Environmental Engineering, University of Iceland \\ IS-107 Reykjavik, Iceland \\ sigurdur.erlingsson@vti.se \\ ${ }^{3}$ School of Sustainable Engineering and the Built Environment, Arizona State University \\ 87-5306, Tempe, Arizona, USA \\ czapata@asu.edu
}




\begin{abstract}
Resilient modulus of unbound materials is an important parameter in the mechanistic design of pavements. Although unbound layers are frequently in a partially saturated state, a total stress approach is conventionally used in modelling the material behaviour and therefore pore pressure effects are not considered. In fine-grained unbound materials, the saturation state can affect their mechanical behaviour due to pore pressure effects. In this study a modified test procedure and a predictive resilient modulus model that takes into account the subgrade soil matric suction as a stress state variable is presented. Two different silty sand subgrade materials were tested in unsaturated conditions using series of repeated load triaxial tests under controlled pore suction conditions to study its influence on the resilient modulus. The test data were further used to obtain the resilient modulus model regression parameters that accounts for moisture content variations through the matric suction parameter. Generally, the prediction model could effectively capture the resilient modulus behaviour of the subgrades with respect to changes in the normal stress state and the matric suction. Given the completeness of this method, this prediction model is recommended as an improved approach in capturing the moisture content effects on the material stiffness properties.
\end{abstract}

Keywords: Subgrade, Resilient Modulus, Unsaturated Soil, Matric Suction, Environmental Effects, Moisture Content. 


\section{INTRODUCTION}

A large part of the operating road network around the world consists of flexible pavement structures with a relatively thin bituminous surface layer $(\leq 100 \mathrm{~mm})$. In thin flexible pavement structures, the function of the supporting unbound layers becomes very significant as they greatly

contribute to the overall stiffness of the pavement system. Therefore, large resilient and permanent deformation of unbound granular layers and subgrade soil greatly contribute to pavement deterioration and surface distresses.

It is known that moisture content is an important factor affecting the mechanical behaviour of pavement unbound materials (Saevarsdottir and Erlingsson 2013; Erlingsson 2010). Recent studies on improvement of design and maintenance methods of low volume roads have shown that, in most cases, the problem is related to accumulation of excess water content in the unbound layers or the subgrade soil (Salour and Erlingsson 2013a; Laloui et al. 2008; Charlier et al. 2008; Aho and Saarenketo 2006; Saarenketo and Aho 2005). This is a common issue in regions where pavement structures are subjected to significant seasonal environmental effects such as high precipitation, groundwater level variations and freeze-thaw actions in cold regions. Therefore, proper consideration of the influence of moisture content on the stress state and hence, on the mechanical behaviour of the unbound materials should be given in any sustainable pavement design and performance prediction model (Santha 1994; Andrei 2003; ARA 2004; Doucet and Doré 2004; Zapata et al. 2007; Cary and Zapata 2010; Rahman and Erlingsson 2012).

One of the important input parameters in flexible pavement design is the stiffness of the unbound layer materials. This material property is widely characterized by the resilient modulus $\left(M_{R}\right)$ using Repeated Load Triaxial (RLT) testing under different stress state and moisture 
conditions. (e.g. when studying seasonal effects). This soil property depends on many factors such as gradation and texture, stress state, compaction energy, dry density, number of load cycles and moisture content (Lekarp et al. 2000). Despite the fact that unbound pavement materials are generally in partially saturated states and are tested in unsaturated conditions in the laboratory, the effect of pore pressures are usually not taken into account and a total stress approach is used when modeling their behaviour. From unsaturated soil mechanics, it is known that variation in the moisture content of fine-grained subgrades results in changes in the stress state of the soil. This can be explained by changes in the soil pore pressure, i.e. the matric suction, $\psi_{m}$. Matric suction is defined as the pressure difference between the pore-air and the pore-water phases in the soil matrix. Therefore, a comprehensive description of fine-grained unbound materials stiffness behaviour requires an effective stress approach in which the pore pressures (suction) are measured or controlled during the load application (Yang et al. 2005; Cary and Zapata 2011; Nowamooz et al. 2011). Using this approach, moisture content effects can be incorporated into stiffness predictive models by integrating matric suction as a stress state variable into the models (Khoury and Zaman 2004). This will further allow accounting for seasonal moisture variations and their effect on the material stiffness.

In this study, series of suction-controlled resilient modulus laboratory tests on compacted subgrades in unsaturated state were conducted using a modified testing procedure based on the axis-translation technique (Fredlund et al. 2012). Two different silty sand subgrade materials, frequently encountered in Nordic countries due to the heterogeneous sedimentation process of glacial origin, were tested. The objectives of this study were to implement a modified suction-controlled resilient modulus testing system for unsaturated subgrades and to investigate the influence of the matric suction (moisture content) on the resilient modulus of silty sand 
subgrade materials. Furthermore, a resilient modulus model that accounts for seasonal moisture changes by incorporating matric suction as a stress state variable was calibrated and evaluated.

\section{MOISTURE IN PAVEMENT UNBOUND MATERIALS}

The moisture balance in the pavement system is continuously evolving over time. During the construction phase, pavement unbound materials are usually compacted at values close to their optimum moisture content and maximum dry density conditions. However, this moisture content will change to a natural equilibrium state that is greatly dependent on environmental conditions, material properties and the groundwater table level. In a study that was carried out by Zapata et al. (2009), 44 subgrade soil samples were collected from 30 pavement sections throughout the United States. The collected samples had in situ degrees of saturations $\left(S_{r}\right)$ varying between $38 \%$ and $97 \%$, with an average value of $79.1 \%$.

The moisture content can still deviate from the equilibrium state due to seasonal climatic factors such as rainfall, groundwater table variations and freeze-thaw actions. Figure 1 shows the monitored moisture content in the subgrade layer over a one year period (July 2010 to June 2011) in a test road section in southern Sweden (Torpsbruk). The test section in Torpsbruk usually experiences a total frost depth close to $1.2 \mathrm{~m}$ in winter. The measurements were done using the Time Domain Reflectometry (TDR) technique. Figure 1 is based on in situ measurements from two moisture rods, each consisting of four moisture probes (Salour and Erlingsson, 2013b). The moisture probes were installed at four different depths, with three of them located in the subgrade. 


\section{[FIGURE 1]}

Considerable moisture content variations were observed in the upper part of the subgrade that were mainly associated with precipitation instances and freeze-thaw cycles. The subgrade moisture content deviated from an equilibrium degree of saturation of approximately $60 \%$ to a nearly fully saturated state during heavy autumn rainfalls and after the thaw penetrated the pavement in the spring period. Knowing the considerable presence and variation of the moisture content and its effect on the behaviour of unbound materials, proper considerations should be given to this factor for a realistic pavement design.

\section{RESILIENT MODULUS MODELLING}

In pavement engineering, the stress caused by traffic load is small compared to the material strength; however, the load is applied a large number of times. The material deformation under each load application can be divided into two parts, the plastic deformation and the recoverable deformation. At the early stage of load application, the plastic deformation is usually considerable but decreases as the number of load repetitions increases. After a sufficient number of cyclic load applications under constant conditions of moisture content, confinement and deviator stress, the deformation almost completely recovers and the plastic strains become very small. Thus, the material behaviour can be considered to be elastic at this stage (Figure 2, left).

The stiffness of pavement unbound materials and the subgrade soils are widely characterized by the resilient modulus parameter $\left(M_{R}\right)$ which is usually obtained from RLT testing. The resilient modulus represents the stress-strain behaviour of unbound materials under repeated traffic loading, analogous to the elastic modulus used in the elastic theory (Huang, 
2004). In RLT testing, the resilient modulus is mathematically defined as the ratio of the cyclic deviator stress $\left(\sigma_{d}\right)$ to the recoverable strain $\left(\varepsilon_{r}\right)$ (Figure 2, right); and it is presented as:

$$
M_{R}=\frac{\sigma_{d}}{\varepsilon_{r}}
$$

\section{[FIGURE 2]}

The resilient modulus should be measured under conditions representative of the stress state and the environment that is experienced by the unbound materials in the pavement system. Several researchers have proposed mathematical models that describe the stress dependence of the resilient modulus using a total stress approach. These models are mainly developed from curve fitting of laboratory triaxial data and do not directly account for environmental factors that are mainly related to variations in the material moisture content (Lekarp et al. 2000). To overcome this drawback, Cary and Zapata (2011) proposed an enhanced resilient modulus model that accounts for seasonal environmental variations by incorporating matric suction as a stress state variable. They obtained sets of regression constants from triaxial experiments on granular base and subgrade materials that are commonly used in the state of Arizona. Their proposed model is presented as:

$$
M_{R}=k_{1} p_{a}\left(\frac{\theta_{\text {net }}-3 \Delta u_{w-s a t}}{p_{a}}\right)^{k_{2}}\left(\frac{\tau_{o c t}}{p_{a}}+1\right)^{k_{3}}\left(\frac{\left(\psi_{m_{0}}-\Delta \psi_{m}\right)}{p_{a}}+1\right)^{k_{4}}
$$

where,

$p_{a}=$ atmospheric pressure (here chosen as $100 \mathrm{kPa}$ ) 
$\theta_{\text {net }}=\theta-3 u_{a}=$ the net bulk stress ( $\theta=$ bulk stress $=\sigma_{1}+\sigma_{2}+\sigma_{3}$ and $u_{a}=$ pore-air pressure)

$\Delta u_{w-s a t}=$ pore-water pressure build-up under saturated conditions $\left(\psi_{m}=0\right)$

$\tau_{\text {oct }}=$ octahedral shear stress $=1 / 3 \sqrt{\left(\sigma_{1}-\sigma_{2}\right)^{2}+\left(\sigma_{1}-\sigma_{3}\right)^{2}+\left(\sigma_{2}-\sigma_{3}\right)^{2}}$

$\psi_{m_{0}}=$ initial matric soil suction and $\Delta \psi_{m}=$ relative change in soil matric suction with respect to

$\psi_{m_{0}}$ due to pore-water pressure build-up under unsaturated conditions ( $\Delta u_{w-s a t}=0$ )

$k_{1} \geq 0, k_{2} \geq 0, k_{3} \leq 0$ and $k_{4} \geq 0$ are regression constants.

In RLT tests, the principal stresses acting on the specimen are: $\sigma_{1}=\sigma_{3}+\sigma_{d}, \sigma_{2}=\sigma_{3}$ and $\sigma_{3}=\sigma_{c}$ where $\sigma_{c}=$ confining pressure and $\sigma_{d}=$ deviator stress. Therefore, $\theta=\sigma_{d}+3 \sigma_{c}$ and $\tau_{\text {oct }}=\sqrt{2} / 3 \sigma_{d}$. In the first factor of the model presented in Eq. (2), the term $\theta_{\text {net }}$ accounts for the shift from an unsaturated to a saturated state. When the $u_{a}$ approaches zero due to increase in water content, the net bulk stress ( $\left.\theta_{\text {net }}\right)$ approaches the bulk stress $(\theta)$. The third factor captures the contribution of matric suction to the resilient modulus under unsaturated conditions.

\section{TEST SOIL MATERIAL}

\subsection{Soil Index Properties}

Two silty sand subgrade soils commonly encountered in Sweden were selected for testing in this study. The subgrade soils were obtained from two different sites in Sweden; the southern part (near Torpsbruk in the Småland province) and the northern part (near Luleå in Norrbotten province) of the country. Wet sieve analysis, specific gravity, maximum dry density, optimum moisture content and Soil-Water Characteristic Curve (SWCC) tests were performed on the selected materials. A summary of the test results is presented in Table 1. Figure 3 shows the grain size distribution curves for the subgrade soils used in this study. 
[TABLE 1]

[FIGURE 3]

\subsection{Soil-Water Characteristic Curve}

Realistic modelling of pavement structural behaviour requires proper consideration of environmental effects. The performance of pavement unbound materials is considerably dependent on the moisture content, which affects their stress state due to changes in the pore pressures, i.e. matric suction. Thus, matric suction can be incorporated into the performance prediction models as a stress state variable. The relationship between the soil moisture content and the matric suction is usually represented by the Soil-Water Characteristic Curve (SWCC). It can be used to estimate various parameters used to describe unsaturated soil behaviour (Fredlund et al. 2012).

The SWCC for the subgrade materials were determined using the SWC-150 Fredlund SWCC device which is an odometer-type apparatus for applying matric suctions from near zero values up to $1500 \mathrm{kPa}$ under various stress paths (GCTS 2007). This device measures the moisture content of the specimen by the amount of water that is released or absorbed by the specimen without disassembling the apparatus between the data points. A saturated ceramic stone with a High Air Entry (HAE) value of $500 \mathrm{kPa}$ was used, which allowed applying suction values up to about $450 \mathrm{kPa}$. This was found to be suitable for the non-plastic subgrade soils tested. The subgrade soils specimens were compacted in the brass ring $(25.4 \mathrm{~mm}$ high and 63.5 
mm wide internal diameter) of the apparatus to reach the maximum dry unit weight obtained from the standard Proctor test. Samples were soaked in distilled water overnight to become fully saturated before testing. Thus, the drying paths of the SWCCs for the subgrade soils were obtained by applying air pressure to the specimens. For each soil, six data points were obtained from each matric suction test. The measured moisture content (degree of saturation) and the corresponding suction value were plotted to obtain the SWCCs. The data points were fitted with a sigmoidal curve using a nonlinear curve-fitting method. These curves were further used to apply the matric suction levels required to reach the target moisture contents for the resilient modulus tests. The SWCCs and test apparatus are presented in Figure 4. As can be seen in Figure 4, the Luleå subgrade had a higher air-entry value compared to the Torpsbruk subgrade. This was due to the higher amount of fine content in Luleå subgrade compared to the Torpsbruk subgrade. Due to the same reason, the Luleå subgrade had considerably higher matric suction at equal degrees of saturations compared to the Torpsbruk subgrade.

\subsubsection{Fredlund and Xing SWCC model}

Among the numerous empirical equations that can formulate the SWCCs, Fredlund and Xing’s (1994) sigmoidal model has been widely used and validated for large ranges of soil types and suction values (Zapata et al., 2000). The model is expressed as:

$$
\begin{aligned}
& w(\psi)=C(\psi) \frac{w_{S}}{\left\{\ln \left[e+\left(\psi / a_{f}\right)^{n_{f}}\right]\right\}^{m_{f}}} \\
& C(\psi)=1-\frac{\ln \left(1+\psi / \psi_{r}\right)}{\ln \left[1+\left(10^{6} / \psi_{r}\right)\right]}
\end{aligned}
$$


where,

$w(\psi)=$ volumetric water content at any suction $\psi$

$w_{s}=$ saturated volumetric water content

$C(\psi)=$ correction factor (primarily a function of residual water content)

$\psi=$ matric suction $(\mathrm{kPa})$

$\psi_{r}=$ soil suction at residual condition $(\mathrm{kPa})$

$a_{f}=$ fitting parameter (related to the soil air-entry value) (kPa)

$n_{f}=$ fitting parameter (related to the rate of desaturation)

$m_{f}=$ fitting parameter (related to the curvature near residual conditions)

The Fredlund and Xing SWCC model parameters obtained through the regression process for the two subgrades are listed in Table 2. The resulting sum of the squared errors (SSE) and the coefficient of determination $\left(R^{2}\right)$ are also presented in Table 2.

[FIGURE 4]

[TABLE 2] 


\section{REPEATED LOAD TRIAXIAL TEST}

\subsection{Testing System and Control Unit}

The materials were tested at the Arizona State University (ASU) Geotechnical Laboratory. The triaxial cell and control unit for unsaturated soils testing at ASU is a custom-built electro-hydraulic system with closed-line fully digital servo controllers that is capable of controlling/measuring the pore-water and pore-air pressure of the soil specimen during the test. This is conducted by using high precision Pressure-Volume Controllers (PVC) that are integrated and controlled by a computer system. The testing system consists of four main components: the unsaturated soil triaxial cell, a micro-console controller, a central pressure unit and the measuring components (load cell and displacement transducers). This test setup allows for independent control of pore-water, pore-air and confinement pressures with automated regulators. Suction control of the test specimen was done using the axis-translation technique. The load sequences used for the resilient modulus testing were in accordance with the NCHRP 1-28A (2004) protocol "Harmonized Test Methods for Laboratory Determination of Resilient Modulus for Flexible Pavement design” after some modifications to the procedure that allowed for testing soil in unsaturated conditions with matric suction control (Cary and Zapata 2011). A schematic overview of the triaxial system is illustrated in Figure 5.

\section{[FIGURE 5]}




\subsection{Axis-Translation Technique and Matric Suction Control}

Unsaturated soils are characterized as a four-phase system: solid phase, air phase, water phase and an air-water interphase or the contractile skin on soil behaviour (Fredlund et al. 2012). In testing unsaturated soils, negative pore-water pressures below $-1 \mathrm{~atm}$. (i.e., $101 \mathrm{kPa}$ gauge) in which water cavitation may occur must be avoided. This will cause difficulties in control or measurement of the pore-water pressure. To overcome this problem, the axis-translation technique is usually employed. In this technique, both pore-air pressure and pore-water pressure are translated into positive pressure ranges, while still maintaining the same matric suction state $\left(u_{a}-u_{w}\right)$ in the specimen. Using this technique, the pore-water pressure can be measured or controlled as no cavitation in the system can occur.

In RLT testing, employing axis-translation technique requires independent control of the pore-air pressure and the pore-water pressure. In modified triaxial cells for unsaturated soil testing, the direct control/measurement of the material pore-air pressure $\left(u_{a}\right)$ can be achieved at the top of the test specimen and the direct control/measurement of the material pore-water pressure $\left(u_{w}\right)$ can be done at both the top and the bottom of the test specimen.

In the triaxial cell used in this study, the pore-water pressure was controlled using the bottom platen which was built-in with a 5-bar HAE ceramic disk similar to the one used in the SWC-150 Fredlund SWCC device. The HAE disk allows the passage of water but prevents the flow of air to the specimen. The pore-air pressure was controlled using the top loading platen which was built in with a porous stone that allowed for application of air pressure to the specimen. The independent control or measurement of pore-air pressure and pore-water pressures by the axis translation technique allows control or measurement of matric suction throughout the tests (Fredlund et al. 2012; Yang et al. 2008). 


\subsection{Test Procedure Overview}

The resilient modulus test procedure consisted of the following stages: The HAE disk was saturated by filling the triaxial cell with distilled water up to a height slightly above the disk. The cell was then subjected to air pressure until the air in the HAE disk dissolved in water and the water flowed through the HAE disk. At this stage, any possible air bubbles that might be trapped under the HAE disk and in the lines were flushed out using the flushing device. After flushing for several times, the specimen was placed on the saturated HAE disk and the membrane was sealed to the pedestal using high vacuum grease and O-rings. The cell pressure, and the pore-air and pore-water pressures needed to achieve the test target matric suction $\left(u_{a}-u_{w}\right)$ were applied. Once the specimen reached the moisture content corresponding to the test target matric suction, the specimen was subjected to the dynamic load sequence for estimation of the resilient modulus.

\subsection{Cyclic Loading and Strain Measurement}

The vertical deformations on the test specimen were measured using two Linear Variable Differential Transformers (LVDTs). The LVDTs were attached on studs that were buried into the specimen during the compaction process. The deformation measurement was done along the middle half of the specimen $(100 \mathrm{~mm})$. The resilient modulus obtained after each loading sequence was then calculated using the average recovered deformations measured by the two LVDTs separately for the previous five load cycles. 


\section{TEST SPECIMEN}

\subsection{Specimen Preparation}

In order to obtain a homogeneous mix, the subgrade materials were thoroughly mixed at their optimum moisture content and stored in a sealed container in a controlled temperature room for approximately 48 hours. Subsequently, the materials were compacted in a rigid mould and in eight layers using a Proctor hammer. The test specimens were cylindrical and had a diameter of $102 \mathrm{~mm}$ and a height of $203 \mathrm{~mm}$ (4 x 8 inch). The compacted specimens had maximum dry densities that were determined from the standard Proctor tests of the soils. The studs that were used for mounting the external LVDTs were buried into the specimen after the second and sixth layers were compacted.

The two subgrades were tested at 4 different moisture contents with two replicates that added up to a total number of 16 completed tests. The four different target moisture contents for resilient modulus tests were the optimum moisture contents as well as the moisture contents corresponding to $30 \%, 50 \%$ and nearly $100 \%$ degree of saturation. Although the suction values used for resilient modulus testing at very low degree of saturations may not be often experienced by subgrade soils in the field, use of these values was considered to be beneficial in the modelling procedure.

[TABLE 3] 


\subsection{Specimen Conditioning}

In the preconditioning process needed to reach the target moisture content for the resilient modulus tests, the specimens were compacted at optimum moisture content and subsequently either saturated or dehydrated to the target moisture content. This process was followed in order to minimize fabric effects on the determination of the resilient modulus. This process was controlled by taking regular measurements of the weight of the specimens. Once the specimen was close to the target moisture content, the latex membrane was assembled and the specimen was stored in a moisture-sealed bag for about 24 hours. During this period, the specimen was intermittently turned upside down to help accelerating the homogeneity in moisture distribution and minimizing gravitational gradients.

The specimen was then mounted on the triaxial cell pedestal. Any air possibly entrapped under the ceramic stone and in the connection lines was flushed out and after applying a suitable confinement pressure the target matric suction value was imposed. In this procedure, under the applied matric suction, the specimen absorbs or releases water until moisture equilibrium is reached. This was the last phase of the moisture equilibration process. Once the equilibration process was completed, the resilient modulus test was started. Since the Luleå subgrade had a higher fine content compared to the Torpsbruk subgrade, it had a higher suction value at a similar degree of saturation, which resulted in a longer moisture equilibration process.

Instead of conducting the preconditioning procedure described in the preceding paragraphs, the specimens could have reached the desired moisture content by only performing the last part of the equilibration process mentioned above (only applying suction to the

compacted specimen that corresponded to the target moisture content). However, this would have resulted in a longer process due to the dimension of the specimen and the fine content of the 
soils. Therefore, and as stated earlier, preconditioning of the specimens was performed prior to the final equilibration phase, which expedited the process.

\subsection{Loading Sequence}

The NCHRP 1 28A (2004) test protocol requires that the resilient modulus of subgrade soil specimens be determined by RLT testing on a cylindrical specimen. In this protocol, the stress paths vary depending on the material classification. In all cases, the test begins with conditioning of the specimen by applying a minimum of 1000 load cycles followed by the corresponding stress path. Each stress path sequence consists of 100 load repetitions with a haversine shaped load pulse. The load pulse consists of a 0.2 second load followed by a 0.8 second rest period.

The loading sequences for the two subgrades were not identical. In the NCHRP 1-28A (2004) test protocol, the loading sequence procedure for the resilient modulus testing of subgrades is divided into two different procedures: Procedure Ib for granular subgrade material and Procedure II for fine-grained subgrade material. According to the test protocol specification, the Torpsbruk subgrade was categorized as granular subgrade and the Luleå subgrade was categorized as fine-grained material. Procedure Ib for granular subgrades consisted of 20 loading sequences as follows: five confining pressures of 13.8, 27.6, 41.4, 55.2 and $82.8 \mathrm{kPa}$ that were applied along with four sets of deviator stresses of 6.9, 13.8, 20.7, 27.6 and $41.4 \mathrm{kPa}$ (set 1); 13.8, 27.6, 41.4, 55.2, and 82.8 kPa (set 2); 27.6, 55.2, 82.8, 110.4 and $165.6 \mathrm{kPa}$ (set 3); 41.4, 82.8, 124.2, 165.6, and 248.4 kPa (set 4). Procedure II for fine-grained subgrades consisted of 16 loading sequences: four confining pressures of 55.2, 41.4, 27.6, and $13.8 \mathrm{kPa}$ that are applied along with four identical sets of deviator stresses of 27.6, 48.3, 69.0, and $96.6 \mathrm{kPa}$. 


\section{TEST RESULTS}

\subsection{Test Data}

Figure 6 presents examples of the stress-strain behaviour of the Luleå subgrade during the resilient modulus test. In these figures, the axial response (axial strain, $\varepsilon_{a}$ ) of the specimen to a set of cyclic stress paths are presented at two different matric suctions (degree of saturation). The figures show the nonlinear behaviour of the subgrade soil to cyclic loading and its sensitivity to the state of stresses.

\section{[FIGURE 6]}

\subsection{Model Parameters}

The regression parameters for the model presented in Eq. (2) were calculated by least square curve fitting on the resilient modulus test data. In total, 123 data points for the Luleå and 150 data points for the Torpsbruk subgrade that corresponded to different combinations of stress invariants and matric suctions were used for this statistical analysis. The Solver function in Microsoft Excel ${ }^{\circledR}$ was used for the model parameters optimization which was set up to minimize the sum of the squared errors between the measured and calculated resilient modulus data.

The coefficient of determination $\left(R^{2}\right)$ and the adjusted coefficient of determination $\left(R_{\text {adj }}^{2}\right)$ were also calculated to evaluate the goodness of fit for the proposed model. Furthermore, the experimental data were also plotted versus the prediction model with the parameters determined from the optimization procedure. The model parameters and the goodness of fit statistics are 
summarized in Table 4. Figure 7 shows the prediction model presented in Eq. (2) together with the measurements for the two subgrade materials.

\section{[TABLE 4]}

\section{[FIGURE 7]}

The regression of the test data yielded $R_{a d j}^{2}$ values of 0.76 and 0.78 for Luleå and Torpsbruk subgrades, respectively. This is considered to be good for unbound subgrade materials which generally show high data scatters in experimental tests such as the resilient modulus. From the graphs plotted in Figure 5 and given the goodness of fit parameters presented in Table 4, it can be concluded that the proposed model that includes matric suction as a fundamental stress variable might be a realistic approach for taking into account the effect of change in the environmental conditions.

\subsection{Result and Discussion}

To illustrate how the stress state variables are incorporated in modelling the resilient modulus behaviour, the experimental data were plotted along with the data estimated with the proposed model. Figures 8 and 9 show the measured and predicted data for the Luleå and the Torpsbruk subgrade materials, respectively. Each sub-figure in Figures 8 and 9 corresponds to a matric suction (degree of saturation) at which the resilient modulus test was performed (as presented in Table 3). A higher degree of saturation, $s_{r}$, corresponded to lower matric suctions. These figures show the sensitivity of the resilient modulus to the bulk stress, the octahedral shear 
stress (directly proportional to the deviator stress in triaxial tests) and to the matric suction (moisture content).

\section{[FIGURE 8]}

In both subgrade materials, the resilient modulus increased with an increase in the bulk stress and decreased with an increase in the octahedral shear stress. The significant effect of the subgrade moisture content on the resilient modulus is also evident as shown in these figures. In both materials, an increase in the moisture content that corresponded to decrease in matric suction resulted in considerable reduction in the resilient modulus. This highlights the necessity for improving resilient modulus predictive models that can sufficiently account for moisture content variations in pavement unbound materials (seasonal environmental effects).

It was further observed that in both subgrade soils, the resilient modulus exhibited a higher sensitivity to the bulk and the octahedral shear stress values at lower degrees of saturation. That is, at lower degrees of saturation, the resilient modulus of the subgrade increased at a higher rate with increase in the bulk stress and decreased at a higher rate with increase in the octahedral shear stress. At high degrees of saturation, the magnitude of the octahedral shear stress had no or insignificant influence on the resilient modulus.

\section{[FIGURE 9]}

Figures 7 and 8 indicate that the predictive model presented in Eq. (2) can appropriately capture the subgrade resilient modulus behaviour with respect to the governing stress state 
variables. It further captures the seasonal moisture content variations by incorporating matric suction changes. This approach may lay the groundwork for a smooth shift from unsaturated to saturated conditions in subgrade soils and result in improved prediction models in pavement design.

The in situ moisture measurements presented in Figure 1 are from the Torpsbruk test site from which the Torpsbruk subgrade material samples were also taken and used in the resilient modulus testing. This figure shows the considerable moisture content variation that was particularly observed in the upper part of the subgrade during a one year period. The subgrade degree of saturation deviated from an equilibrium state of about $60 \%$ to about a fully saturated state during the autumn rainfall events as well as the spring thaw period. This corresponded to a matric suction variation from about $40 \mathrm{kPa}$ to less than $5 \mathrm{kPa}$ for the Torpsbruk subgrade (Figure 3). From the resilient modulus tests results and for an arbitrary confinement stress of $27.6 \mathrm{kPa}$ and a deviator stress of $13.8 \mathrm{kPa}$, this change in degree of saturation (matric suction) resulted in a resilient modulus decrease from $205 \mathrm{MPa}$ to $118 \mathrm{MPa}$ (42\% stiffness reduction).

\section{CONCLUSIONS}

Moisture content of pavement unbound layers is continuously evolving over time due to seasonal environmental effects. In fine-grained unbound materials, moisture content variations can change the state of stress through pore pressure effects (suction) that can affect the material stiffness properties. Traditionally, the resilient modulus of subgrade soils is determined in the laboratory using repeated load triaxial testing in which the matric suction is not measured or controlled. In this study, several resilient modulus tests were conducted on two silty sand subgrade soils and at four different matric suctions using the axis-translation technique. These 
matric suctions corresponded to a range of degrees of saturation that can be experienced by subgrade materials in the field due to the environmental effects. The laboratory data clearly indicated that the dependency of the subgrade response to the bulk and octahedral shear stress states was also affected by the matric suction. In the Luleå subgrade, a change in the degree of saturation from $30 \%$ to a near saturated state resulted in a matric suction reduction from $444 \mathrm{kPa}$ to about $7 \mathrm{kPa}$. For the Torpsbruk subgrade, this reduction was from $316 \mathrm{kPa}$ to almost zero since it had less fine content. An increase in matric suction resulted in a decrease in recoverable strains and therefore an increase in the resilient modulus.

The laboratory test results clearly showed that the material suction state affected the sensitivity of the resilient modulus to the bulk and octahedral shear stresses. Therefore, incorporating suction variables (i.e. matric suction) into the resilient modulus predictive models could improve their performance when seasonal moisture fluctuation in unbound fine-grained materials is concerned.

Furthermore, a resilient modulus model that incorporated matric suction as a stress state variable was employed. Using the laboratory test data, the regression parameters of the model were determined. It was observed that the prediction model could successfully simulate the resilient behaviour of the subgrades and its seasonal variations. The prediction model showed good agreement with the experimental data. Given the goodness of fit of the prediction model, it can be concluded that considering matric suction as a stress state variable that can incorporate environmental effects into the resilient modulus predictive model might be a rational approach.

It is believed that a more extensive database with more tests and materials is required to validate the approach and improve or calibrate the model presented in this study. The major concern for this methodology is that this type of unsaturated testing is time-consuming. 
Furthermore, triaxial systems that are capable of measuring matric suction under cyclic loading are mainly limited to research institutes. However, given the fact that field measurements of moisture content in real pavement structures have become more practicable over the recent years and the availability of SWCCs predicting models for various materials and based on simple index properties such as grain size distribution and Plasticity index, the presented matric suction

procedure might be a practical and rational approach to account for seasonal variation of subgrade resilient modulus. The authors recommend more research works to be carried out to further develop the approach that is believed to be a step forward to realistic pavement modelling.

\section{ACKNOWLEDGEMENTS}

This study was sponsored by the Swedish Transport Administration (Trafikverket) and the Fredrik Bachmans Memorial Foundation (Stiftelsen Fredrik Bachmans Minnesfond). This support is gratefully acknowledged. The authors would also like to thank Mr Peter Goguen, Laboratory Manager, and Mr Kenneth Witczak, Laboratory Coordinator, at Arizona State University, School of Sustainable Engineering and the Built Environment, for their technical support and assistance.

\section{REFERENCES}

Aho, A., and Saarenketo, T. 2006. Design and Repair of Roads Suffering Spring Thaw Weakening, The ROADEX III Project, Northern Periphery. 
Andrei, D. 2003. Development of a Predictive Model for the Resilient Modulus of Unbound Materials, Doctoral Dissertation, Arizona State University, Tempe, Arizona.

ARA, Inc., ERES Consultants Division. 2004. Guide for Mechanistic-Empirical Design of New and Rehabilitated Pavement Structures. Final report, NCHRP Project 1-37A. Transportation Research Board of the National Academies, Washington, D.C. (Available at: http:// www.trb.org/mepdg/)

ASTM Standard D698-00a. Standard Test Methods for Laboratory Compaction Characteristics of Soil Using Standard Effort $\left(12,400 \mathrm{ft}-\mathrm{lbf} / \mathrm{ft}^{3}\left(600 \mathrm{kN}-\mathrm{m} / \mathrm{m}^{3}\right)\right)$. ASTM International, West Conshohocken, PA. doi: 10.1520/D698-00a, 2000. (Available at www.astm.org).

Cary, C.E. and Zapata, C.E. 2011. Resilient Modulus Testing for Unsaturated Unbound Materials, Road Materials and Pavement Design, 12(3): 615-638.

Cary, C.E. and Zapata, C.E. 2010. Enhancement of the Model for Resilient Response of Soils due to Seasonal Environmental Changes Implemented in the M-EPDG. Transportation Research Record: Journal of the Transportation Research Board, 2170: 36-44.

Charlier, R., Hornych, P., Srsen, M., Hermansson, A. Bjarnason, G., Erlingsson, S. and Pavsic, P. 2008. Water Influence on Bearing Capacity and Pavement Performance: Field Observations In: Dawson, A. Water in Road Structures; Movement, Drainage and Effects, Springer, pp. 175-214.

Doucet, F. and Doré, G. 2004. Resilient Modulus and Resilient Poisson Coefficient of the C-LTTP Granular Materials. Proceedings of the Annual Conference of the Canadian Geotechnical Society, Canadian Geotechnical Society, Quebec City, Canada. 
Erlingssson, S. 2010. Impact of Water on the Response and Performance of Pavement Structure in an Accelerated Test, Road Materials and Pavement Design, 11(4): 863-880.

Fredlund, D.G., Rahardjo, H. and Fredlund, M.D. 2012. Unsaturated Soil Mechanics in Engineering Practice, Chapter 5, John Wiley \& Sons, Inc.

Fredlund, D.G. and Xing, A. 1994. Equations for the Soil-Water Characteristic Curve, Canadian Geotechnical Journal, 31(3): 521-532.

Huang, Y.H. 2004. Material Characterization In: Pavement Analysis and Design 2nd ed., Prentice-Hall, Inc., pp. 279-333.

Khoury, N. N. and Zaman, M. 2004. Correlation between Resilient Modulus, Moisture Variation and Soil Suction for Subgrade Soils, Transportation Research Record: Journal of the Transportation Research Board, 1874: 99-107.

Laloui, L., Charlier, R., Chazallon, C. Erlingsson, S., Hornych, P., Pavsic, P. and Srsen, M. 2008. Water Influence on Mechanical Behaviour of Pavements: Constitutive Modelling In: Dawson, A. Water in Road Structures: Movement, Drainage and Effects, Springer, pp.193-216.

Lekarp, F., Isacsson, U. and Dawson, A. 2000. State of the Art. I: Resilient Response of Unbound Aggregates. Journal of Transportation Engineering, 126(1): 66-75.

Nowamooz, H., Chazallon, C., Arsenie, M. I., Hornych, P. and Masrouri, F. 2011. Unsaturated Resilient Behavior of a Natural Compacted Sand, Journal of Computers and Geotechnics, 38(4): 491-503.

NCHRP 1-28A, 2004. National Cooperative Highway Research Program, Laboratory Determination of Resilient Modulus for Flexible Pavement Design, In Research Results Digest, No. 285, Transportation Research Board of the National Academies, Washington, D.C. 
Rahman, M.S. and Erlingsson, S. 2012. Moisture Sensitivity of Unbound Granular Materials. Proceedings of the 4th European Pavement and Asset Management Conference (EPAM 4). CD-ROM., Malmö, Sweden.

Salour, F. and Erlingsson, S. 2013a. Moisture Sensitive and Stress Dependent Behavior of Pavement Unbound Materials from Insitu Falling Weight Deflectometer Tests. Transportation Research Record: Journal of the Transportation Research Board, 2335: 121-129.

Salour, F. and Erlingsson, S. 2013b. Investigation of a Pavement Structural Behaviour during Spring Thaw Using Falling Weight Deflectometer, Road Materials and Pavement Design, 14(1): 141-158.

Saevarsdottir, T. and Erlingsson, S. 2013. Water Impact on the Behaviour of Flexible Pavement Structures in an Accelerated Test, Road Materials and Pavement Design, 14(2): 256-277.

SWC-150 Fredlund Soil Water Characteristic Device, User’s Guide and Reference Manual, Version 1.1, 2007. Geotechnical Consulting \& Testing Systems (GCTS) L.L.C., (Available at: www.gcts.com).

Saarenketo, T. and Aho, S. 2005. Managing Spring Thaw Weakening on Low Volume Roads: Problem Description, Load Restriction, Policies, Monitoring and Rehabilitation, The ROADEX II, Northern Periphery.

Santha, B.L. 1994. Resilient Modulus of Subgrade Soils: Comparison of Two Constitutive Equations, Transportation Research Record: Journal of the Transportation Research Board, 1462: 79-90. 
Yang, S.R., Lin, H.D., Kung, H.S. and Huang, W.H. 2008. Suction-Controlled Laboratory Test on Resilient Modulus of Unsaturated Compacted Subgrade Soils. Journal of Geotechnical and Geoenvironmental Engineering, 134(9): 1375-1384.

Yang, S.R., Huang, W.H. and Tai, Y.T. 2005. Variation of Resilient Modulus with Soil Suction for Compacted Subgrade Soils. Transportation Research Record: Journal of the Transportation Research Board, 1913: 99-106.

Zapata, C.E., Perera Y.Y. and Houston, W.N. 2009. Matric Suction Prediction Model in New AASHTO Mechanistic-Empirical Pavement Design Guide. In Transportation Research Record: Journal of the Transportation Research Board, 2101: 53-62.

Zapata, C.E., Andrei, D., Witczak, M.W. and Houston, W.N. 2007. Incorporation of Environmental Effects in Pavement Design, International Journal of Road Materials and Pavement Design, 8(4): 667-693.

Zapata, C.E., Houston, W.N, Houston, S.L. and Walsh, K.D. 2000. Soil-Water Characteristic Curve Variability, Advances in Unsaturated Geotechnics, Geotechnical Special Publication No. 9: 84-124.

\section{LIST OF TABLES:}

TABLE 1. Summary of the subgrade soil index properties 


\begin{tabular}{|c|c|c|c|c|c|c|}
\hline $\begin{array}{l}\text { Subgrade } \\
\text { Soil }\end{array}$ & $\begin{array}{l}\text { USCS } \\
\text { Class }\end{array}$ & $\begin{array}{c}\text { Passing } \\
\text { No. } 200(\%)\end{array}$ & $\begin{array}{c}\text { Maximum Dry } \\
\text { Unit Weight } \\
\gamma_{\text {dmax }}\left(\mathbf{k N} / \mathbf{m}^{3}\right)\end{array}$ & $\begin{array}{c}\text { Opt. Moisture } \\
\text { Content } \\
w_{\text {opt }}(\%)\end{array}$ & $\begin{array}{c}\text { Specific } \\
\text { Gravity } \\
(-)\end{array}$ & $\begin{array}{l}\text { Plasticity } \\
\text { Index (-) }\end{array}$ \\
\hline Luleå & SM & 42.2 & 19.6 & 10.1 & 2.68 & Non-Plastic \\
\hline Torpsbruk & SM & 27.4 & 20.3 & 7.6 & 2.67 & Non-Plastic \\
\hline
\end{tabular}

${ }^{*}$ USCS = Unified Soil Classification System

${ }^{\dagger}$ Maximum dry unit weight is based on standard Proctor compaction test (ASTM D698)

TABLE 2. Fredlund and Xing (1994) curve fitting parameters for the subgrade soils

\begin{tabular}{lccccccc}
\hline & \multicolumn{5}{c}{ Model Parameters } & & \\
\cline { 2 - 5 } & $\psi_{r}(\mathrm{kPa})$ & $a_{f}(\mathrm{kPa})$ & $n_{f}(-)$ & $m_{f}(-)$ & SSE & $R^{2}$ \\
\hline Luleå Subgrade & 17.00 & 34.08 & 5.59 & 0.31 & 0.02 & $>0.9$ \\
\hline Torpsbruk Subgrade & 4.85 & 16.88 & 3.34 & 0.34 & 0.80 & $>0.9$ \\
\hline
\end{tabular}

TABLE 3. Target degree of saturation, corresponding moisture content and calculated matric suction for resilient modulus testing of the subgrade soils

\begin{tabular}{lcccccccc}
\hline & \multicolumn{3}{c}{ Luleå Subgrade } & \multicolumn{4}{c}{ Torpsbruk Subgrade } \\
\hline Degree of Saturation, $S_{r}(\%)$ & 30.0 & 50.0 & $79.3^{\dagger}$ & 94.3 & 30.0 & 50.0 & $70.1^{\dagger}$ & 97.1 \\
\hline Moisture Content, $w \mathbf{( \% )}$ & 3.8 & 6.4 & $10.1^{\dagger}$ & 12.0 & 3.6 & 5.4 & $7.6^{\dagger}$ & 10.4 \\
\hline Matric Suction, $\psi_{m_{0}} \mathbf{( k P a )}$ & 443.9 & 81.0 & $35.0^{\dagger}$ & 6.7 & 316.0 & 51.6 & $23.3^{\dagger}$ & 0.0 \\
\hline
\end{tabular}

\footnotetext{
${ }^{\dagger}$ Measurement corresponding to the optimum moisture content.
}

TABLE 4. Resilient modulus model regression parameters for the subgrade soils

$$
\text { Model Parameters Goodness of Fit }
$$




\begin{tabular}{lcccccc}
\hline & $k_{1}$ & $k_{2}$ & $k_{3}$ & $k_{4}$ & $R^{2}$ & $R_{\text {adj }}^{2}$ \\
\hline Luleå Subgrade & 1489 & 0.746 & -2.633 & 0.434 & 0.761 & 0.759 \\
\hline Torpsbruk Subgrade & 1524 & 0.774 & -1.470 & 0.475 & 0.785 & 0.784 \\
\hline
\end{tabular}

\section{LIST OF FIGURES AND CAPTIONS:}




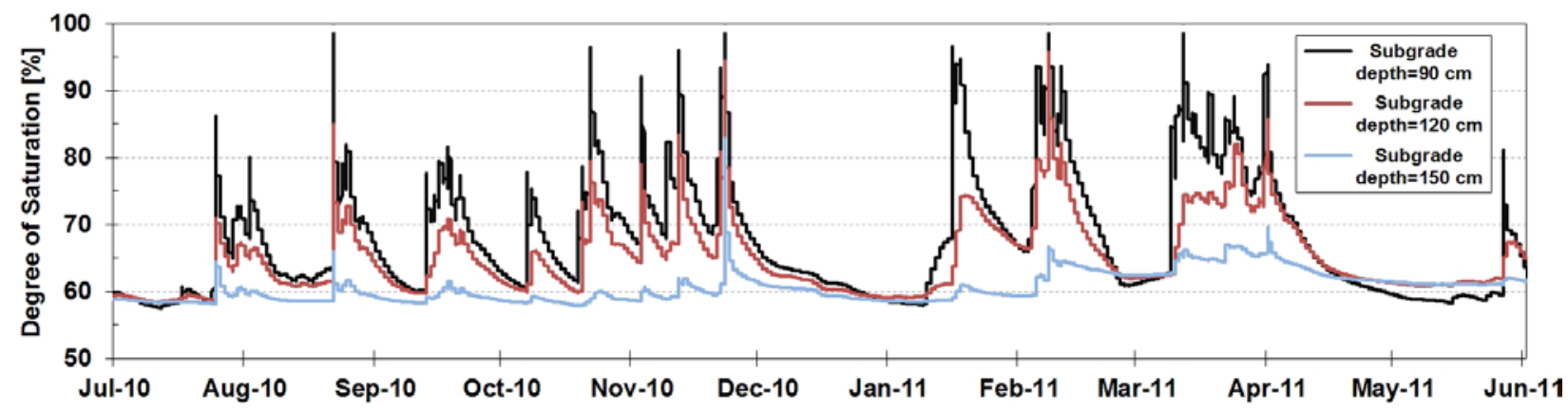

FIGURE 1. Degree of saturation variations in the subgrade soil of a road structure in Torpsbruk (measurements from the unpaved shoulder of the pavement)

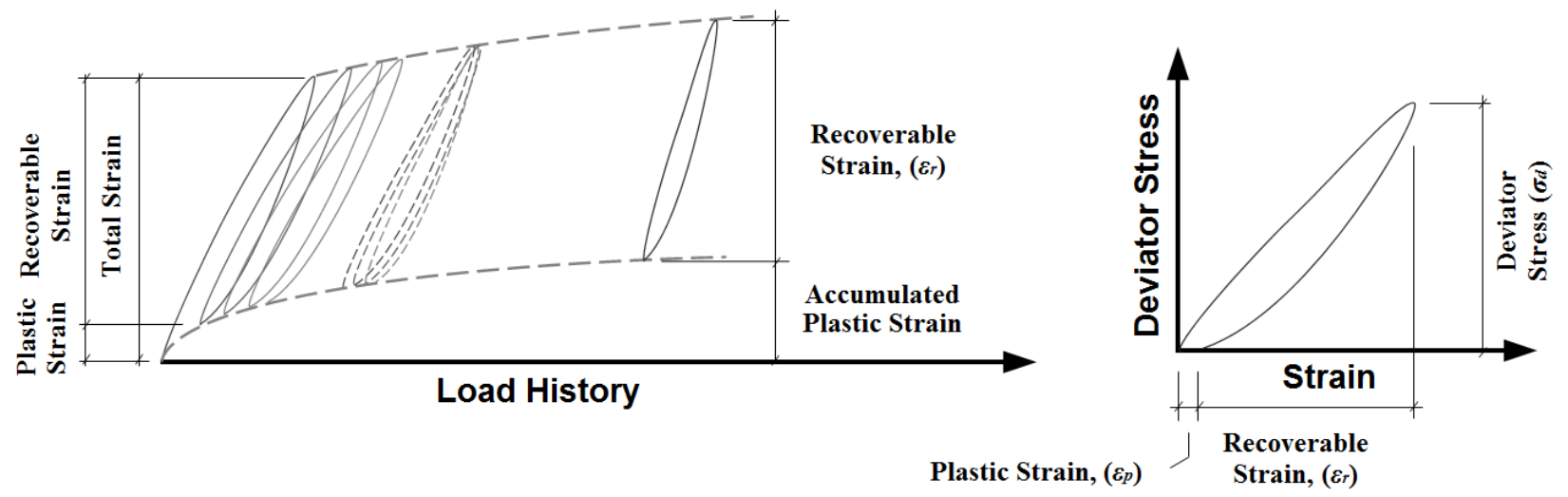

FIGURE 2. Straining of pavement unbound materials under repeated traffic load (left), definition of Resilient Modulus (right) 


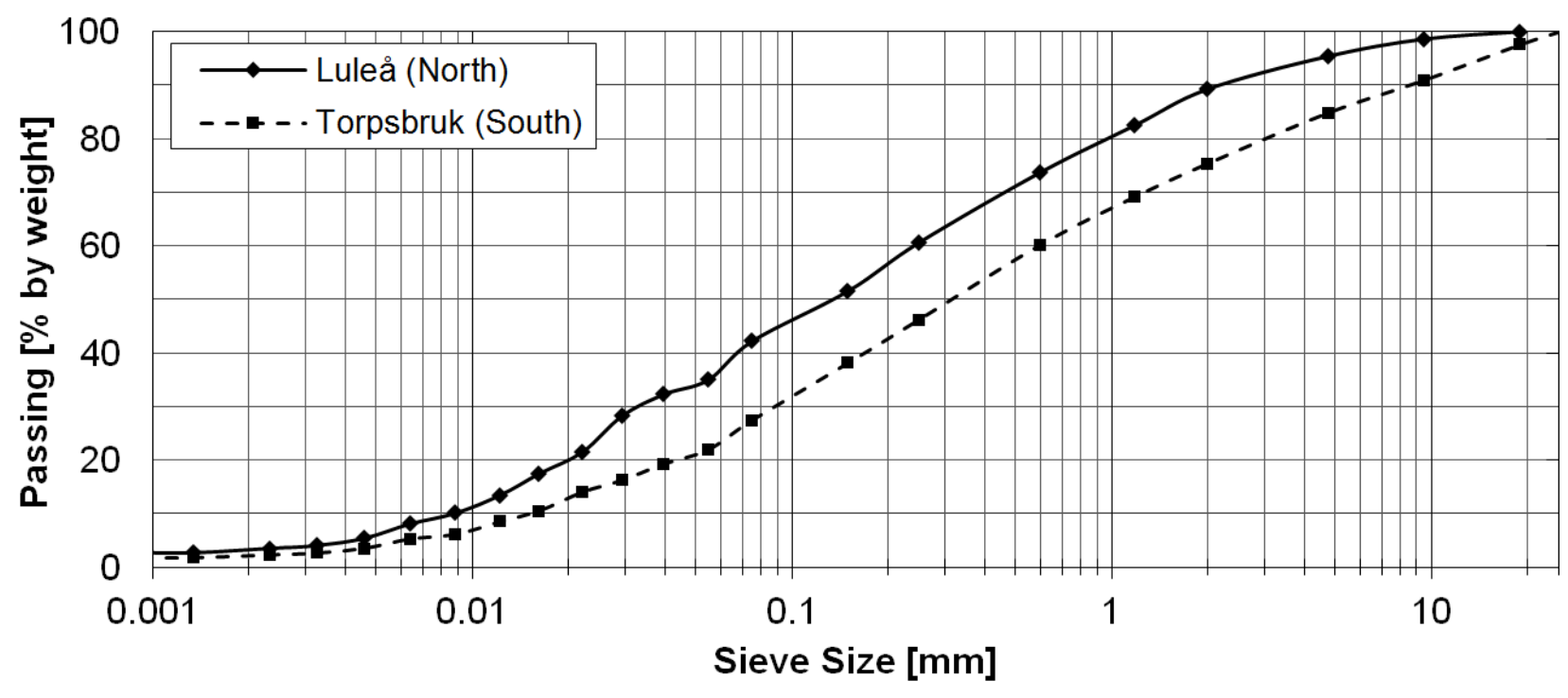

FIGURE 3. Subgrade soil grain size distributions

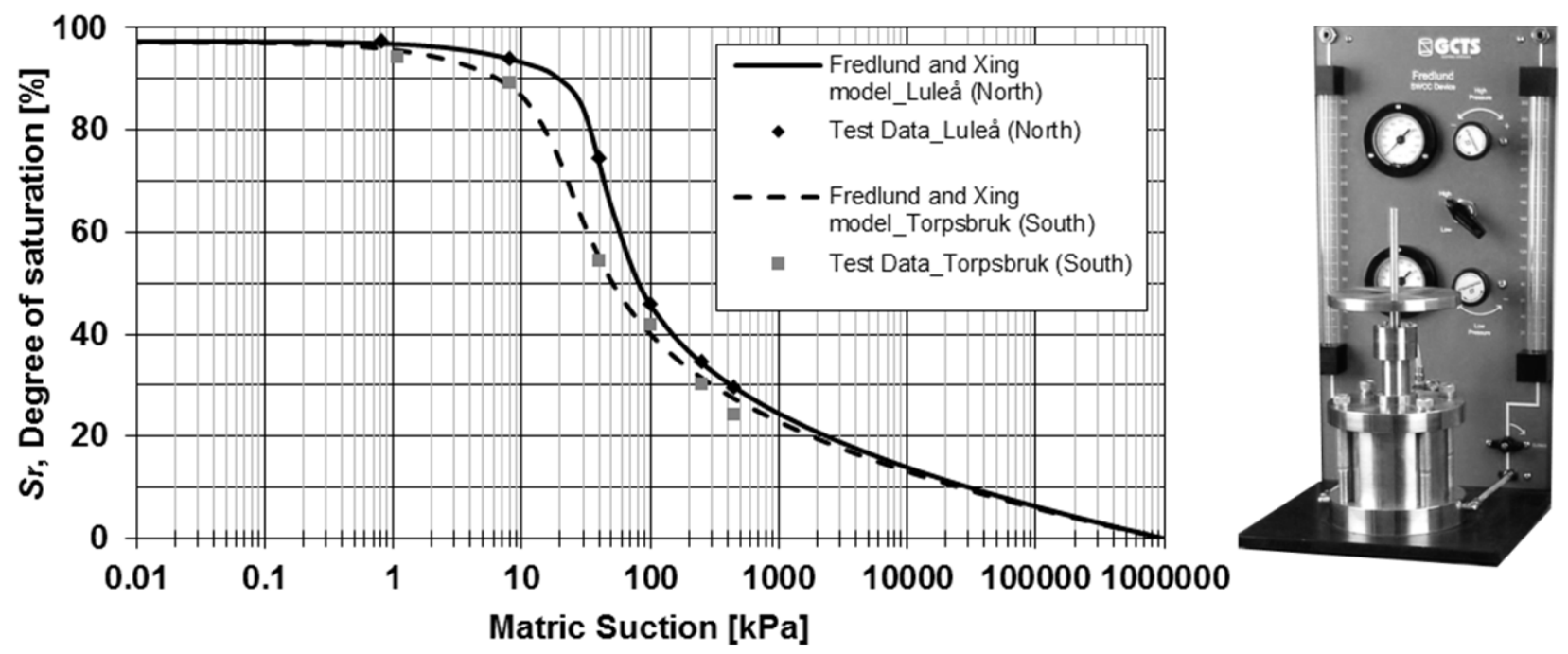

FIGURE 4. SWCC for S-subgrade materials (left), Fredlund SWCC apparatus (right) 


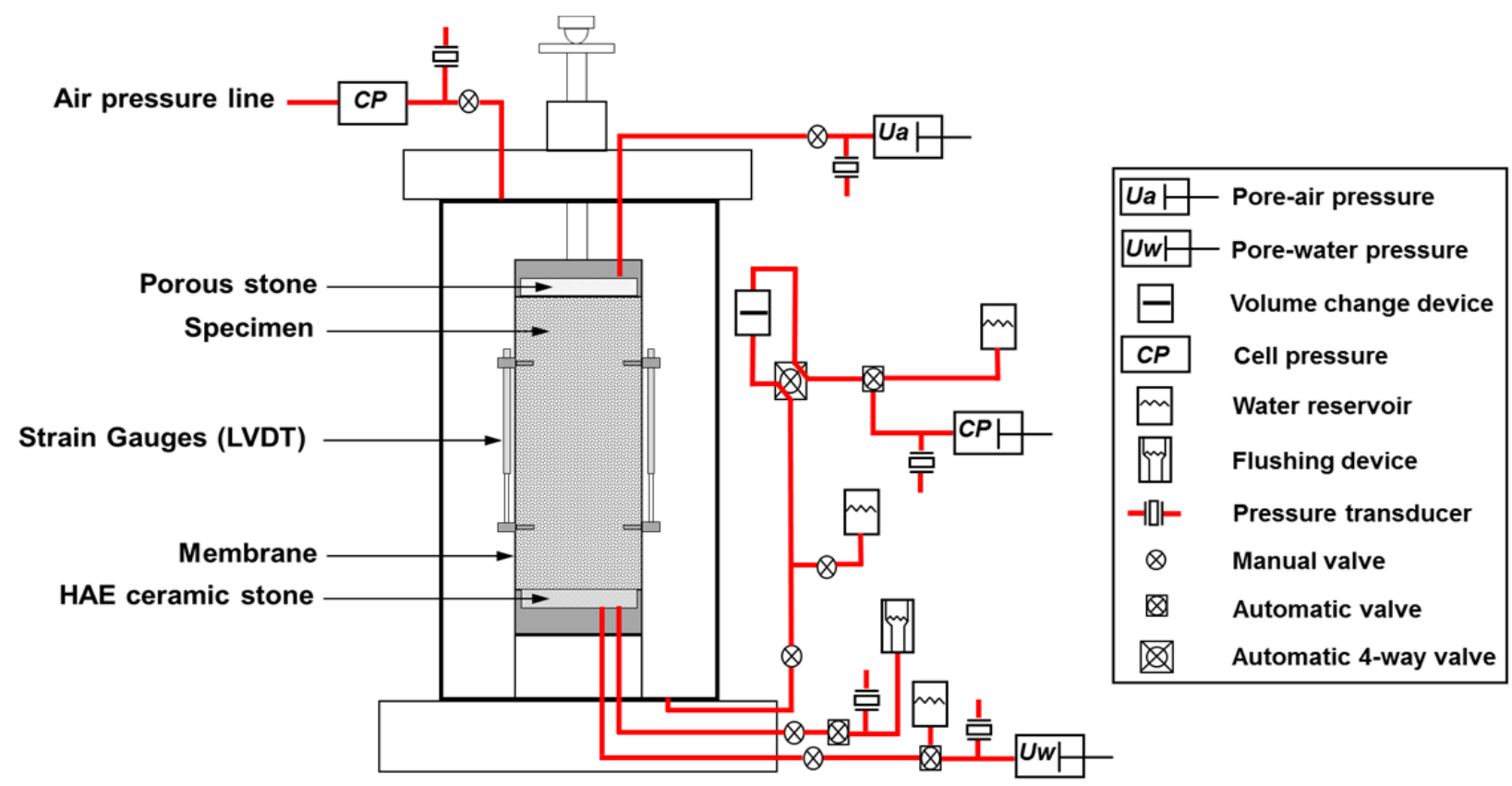

FIGURE 5. Schematic overview of the unsaturated soil triaxial testing system at Arizona State University
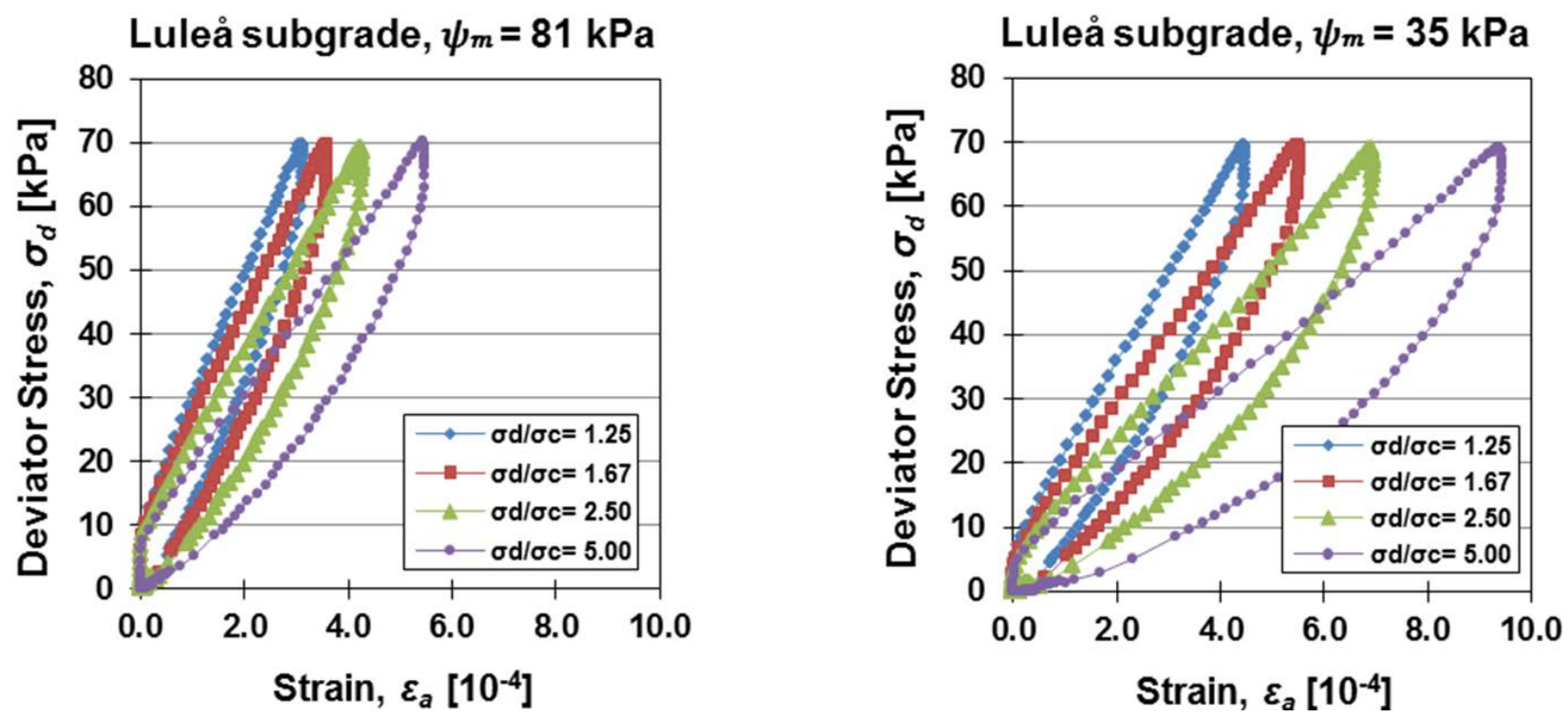

FIGURE 6. Selected resilient modulus test data set for Luleå subgrade at two different matric suctions ( $\sigma_{d}=$ deviator stress and $\sigma_{c}=$ confinement stress) 

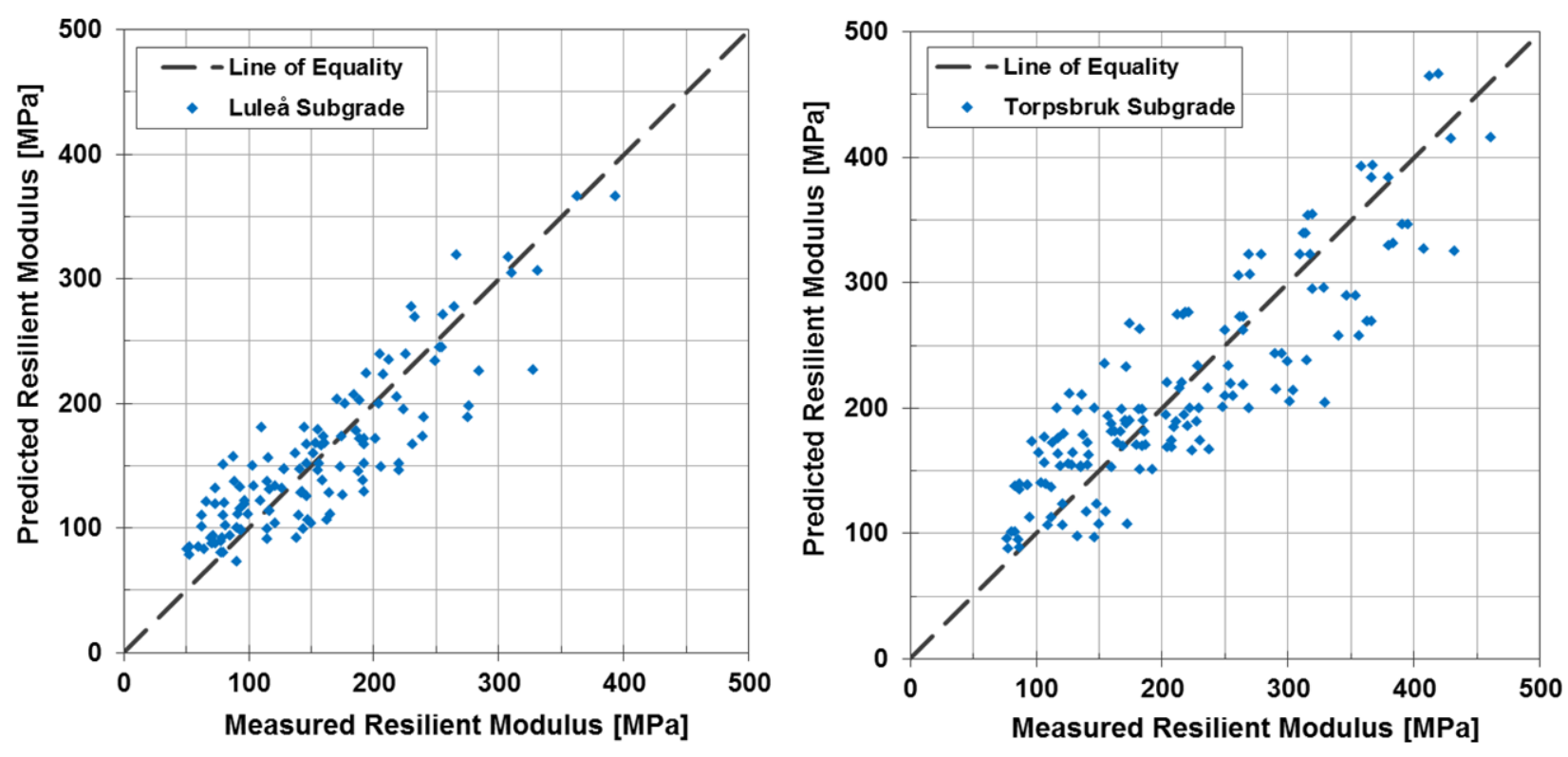

FIGURE 7. Actual versus predicted resilient modulus obtained with the Cary and Zapata model for Luleå subgrade (left) and Torpsbruk subgrade (right) 

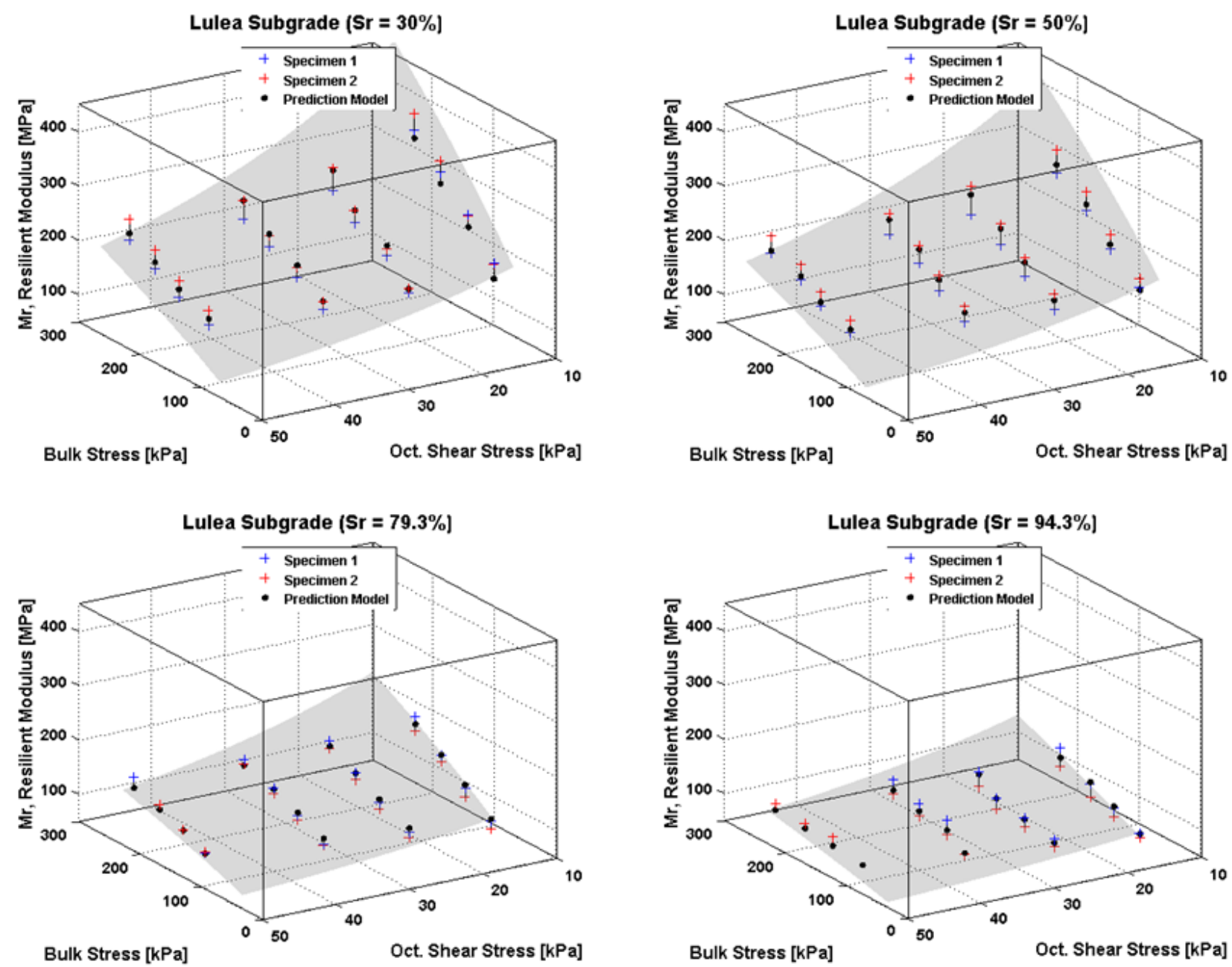

FIGURE 8. Resilient modulus of Luleå subgrade soil at different suction states (degrees of saturation) 


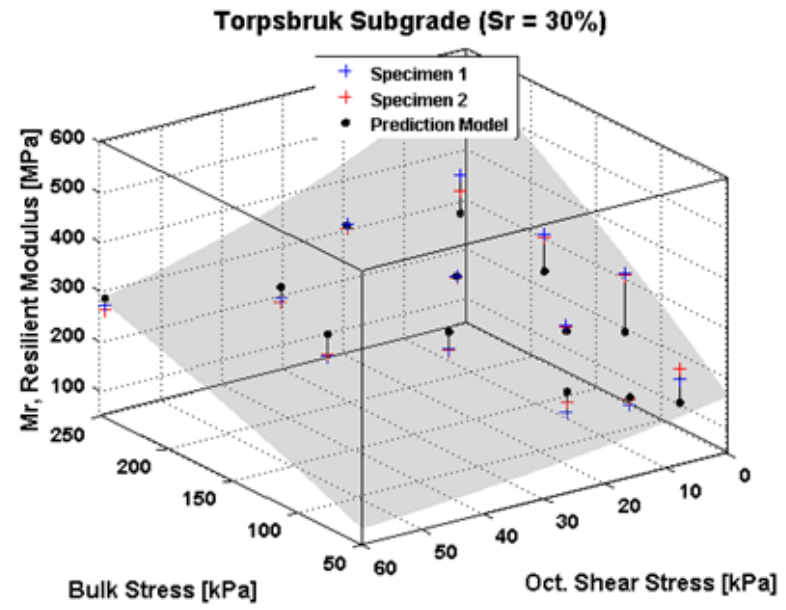

Torpsbruk Subgrade $(\mathrm{Sr}=\mathbf{7 0 . 1} \%$ )

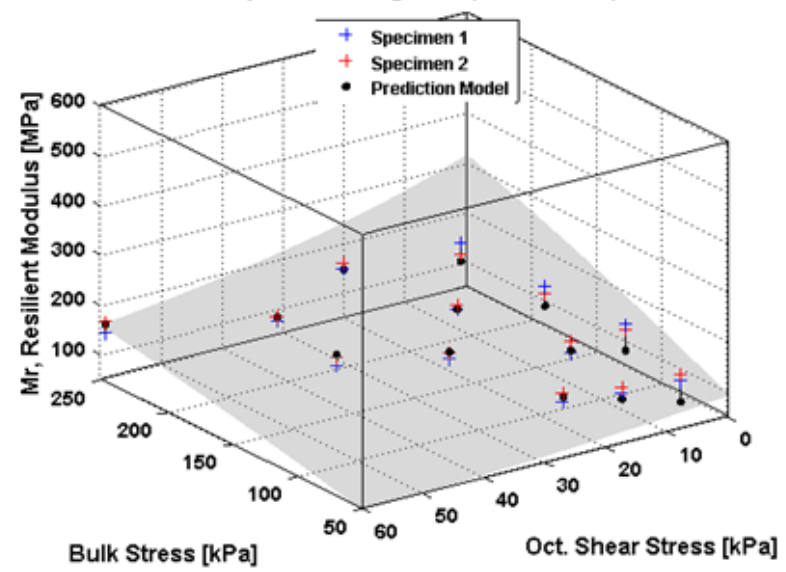

Torpsbruk Subgrade $(\mathrm{Sr}=\mathbf{5 0} \%)$

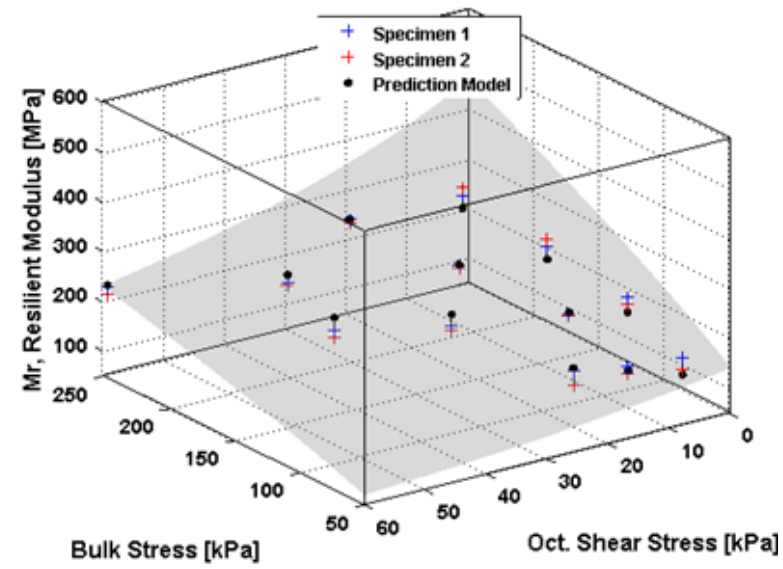

Torpsbruk Subgrade $(\mathrm{Sr}=\mathbf{9 4 . 3} \%$ )

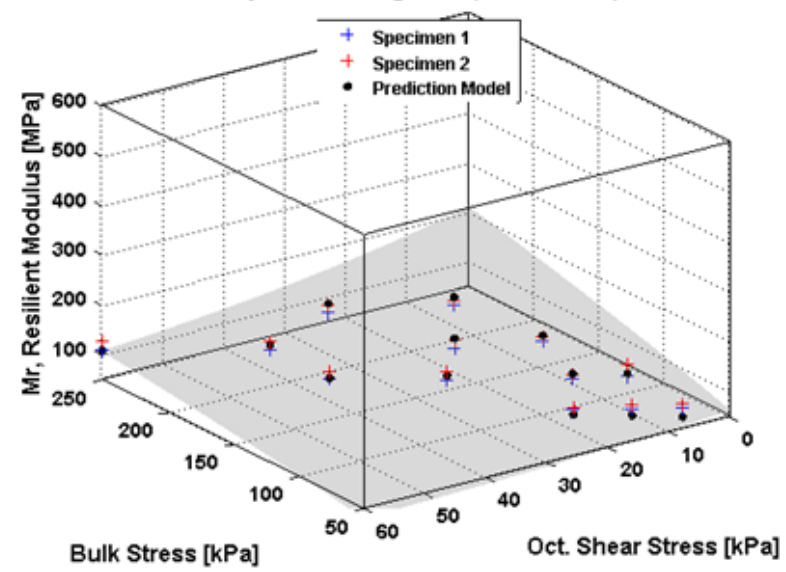

FIGURE 9. Resilient modulus of Torpsbruk subgrade at different suction states (degrees of saturation) 